\title{
ENSAIO TERAPÊUTICO COM GLUCANTIME EM SAGÜIS (CALLITHRIX JACCHUS) INFECTADOS COM UMA CEPA DE LEISHMANIA DONOVANI APARENTEMENTE RESISTENTE AO TRATAMENTO.
}

\author{
R. Dietze, R.C. Araújo, M.L.R. Lima, J.A. Vexenat, P.D. Marsden e A.C. Barreto.
}

\begin{abstract}
Os autores relatam o resultado de um ensaio terapêutico em sagüis com uma cepa de Leishmania donovani isolada de um caso humano fatal de calazar, clinicamente resistente aos antimoniais (Glucantime e Pentostam), Anfotericina B e Pentamidina. Os testes cutâneos realizados no paciente para avaliação da imunidade celular foram negativos à exceçâo do DNCB a $2 \%$. Quatro sangüis adultos (Callithrix jacchus) foram inoculados por via intraperitoneal com uma suspensão de formas amastigotas de $\mathbf{L}$. donovani. Duzentos e dez dias após, todos os animais mostravam formas amastigotas do protozoário, evidenciadas através de punção hepática por aspiração. Iniciou-se então um esquema terapêutico com glucantime ( $28 \mathrm{mgSb} / \mathrm{kg} /$ dia) em três séries de 10 dias com cinco dias de intervalo entre elas em três dos primatas, ficando o quarto animal como controle. Nos três animais tratados houve cura parasitológica da doença, o mesmo não ocorrendo com o controle. O fato de a amostra de L. donovani ter sido, no paciente, resistente aos vários tratamentos e ter sido sensivel em modelo experimental $\dot{a}$ terapêutica com glucantime, sugere a possibilidade de que fatores imunológicos do paciente possam ter contribuído para a evolução fatal da doença.

Palavras Chaves: Calazar. Resistência ao tratamento. Infecção experimental em sagüis.
\end{abstract}

Semelhantemente ao que ocorre no tipo indiano, a leishmaniose visceral no novo mundo responde bem à terapêutica com os antimoniais pentavalentes ${ }^{13}$. No Brasil casos esporádicos de não resposta clínica a esses medicamentos tèm sido relatados, obrigando o uso de drogas alternativas $2 \cdot 121618$.

As razões para essa falha de resposta a terapêutica ainda não foram totalmente elucidadas. No entanto, vários fatores tem sido sugeridos como responsáveis por esse fenômeno como por exemplo resistência do parasito à medicação 4 , resposta imunitária deficiente do hospedeiro ao parasito e fatores farmacodinâmicos da terapia com os antimoniais 314 .

$O$ presente trabalho trata de um ensaio terapêutico experimental em sagüis, de uma amostra de Leishmania donovani isolada de um caso fatal de calazar, clinicamente resistente aos antimoniais (Glucantime e Pentostam), Anfotericina B e pentamidina.

Faculdade de Ciências da Saúde - Núcleo de Medicina Tropical e Nutrição, Universidade de Brasília, Brasilia, DF 70.910 - Brasil.

Este trabalho recebeu suporte financeiro do UNDP/World Bank/WHO Special Programme for Research and Training in Tropical Diseases Projeto No 790356.

Recebido para publicação em 17/8/1984.

\section{MATERIAL E MÉTODOS}

Em maio de 1980 foi internado no Hospital Presidente Médici (Brasilia) o paciente J.T. de 8 anos de idade, natural de It:birina de Mantena (MG), procedente de Vitória (ES), com diagnóstico clínico, laboratorial e parasitológico de calazar. A criança apresentava história de três anos de evolução da doença já tendo sido medicada sem sucesso na ocasião com Glucantime, $28 \mathrm{mgSb} / \mathrm{kg} /$ dia em três séries de 10 dias cada, com sete dias de intervalo entre elas e duas séries de Anfotericina B, $1 \mathrm{mg} / \mathrm{kg}$ em dias alternados, com dose total de $600 \mathrm{mg}$ e $1000 \mathrm{mg}$.

Durante o período em que esteve internado em Brasilia, foram feitos os seguintes esquemas terapêuticos:

- Glucantime ( $28 \mathrm{mgSb} / \mathrm{kg} / \mathrm{dia})$, EV em quatro séries de 10 dias com uma semana de intervalo entre elas.

- Pentamidina (Lomidine) $4 \mathrm{mg} / \mathrm{kg} / \mathrm{dia}, \mathrm{IM}$ durante 15 dias.

- Pentostam $10 \mathrm{mgSb} / \mathrm{kg} / \mathrm{dia}$ EV + Alopurinol $20 \mathrm{mg} / \mathrm{kg} /$ dia VO durante 30 dias.

Como em nenhum dos esquemas empregados houvesse negativação do parasito no aspirado de medula ćssea, optou-se pela esplenectomia associada 
Dietze $R$, Araújo RC, Lima MLR, Vexenat JA, Marsden PD, Barreto AC. Ensaio terapêutico com glucantime em sagüis (Callithrix facchus) infectados com uma cepa de Leishmania donovani aparentemente resistente ao tratamento. Revista da Sociedade Brasileira de Medicina Tropical 18: 39-42, Jan-Mar, 1985

a quimioterapia com Glucantime, tendo porém o paciente falecido antes da realização da mesma, em decorrência de uma septicemia bacteriana.

As provas cutâneas para avaliação da imunidade celular foram todas negativas, à exceção do dinitroclorobenzeno a $2 \%$, e incluiram o PPD, tricofitina, candidina, leishmanina e estreptodornase.

A amostra de $L$. donovani utilizada no estudo, foi isolada em hamster e cultura (Agar Sangue Difco ${ }^{20}$ ) a partir de aspirado de medula óssea do paciente.

Quatro sagüis adultos,Callithrix jacchus, 250g$350 \mathrm{~g}$, do sexo masculino, capturados em Milagres (BA), e adaptados ao cativeiro, foram inoculados por via intraperitoneal com $1,5 \mathrm{ml}$ de uma suspensão de baço e figado de hamster, rica em amatigotas de $L$. donovani. Duzentos e dez dias após a inoculação procedeu-se a punção hepática por aspiração nos quatro animais, com uma agulha $18 \times 11 / 2$ " adaptada a uma seringa descartável de $5 \mathrm{ml}$. O esfregaço obtido à partir desse material foi corado pelo Giemsa para evidenciação do protozoário.

Iniciou-se então esquema terapêutico com Glucantime $28 \mathrm{mgSb} / \mathrm{kg} / \mathrm{dia}$, IM em três séries de 10 dias com cinco dias de intervalo entre elas em três dos primatas, ficando o quarto como controle. Dentre os animais tratados, dois foram sacrificados na terceira semana e um outro juntamente com o controle (não tratado) na quarta semana após o término do tratamento. A presença ou ausência de $L$. donovani nos tecidos dos animais foi determinada por:

- "Imprints" de baço, figado e esfregaço de medula óssea femural com posterior coloração pelo Giemsa.
Cultura de homogenado de baço, fígado e sangue nos meios de $\mathrm{Lit}^{5}$, Agar Sangue Difco ${ }^{20}$ e Schneider ${ }^{11}$, contendo 200 UI de penicilina cristalina e 200 ug de estreptomicina, sendo, para cada amosta, empregados dois tubos de cultura, com observação por 90 dias.

- Exames de cortes histológicos de baço e fígado com coloração pela hematoxilina e eosina.

- Inoculação em dois hamsters pela via intraperitoneal de $1,5 \mathrm{ml}$ de suspensão de baço e fígado dos primatas tratados. Os hamsters foram sacrificados 90 dias após a inoculação, sendo a pesquisa do parasito realizada através de "imprints" do figado, baço e esfregaço de medula óssea corados pelo Giemsa.

\section{RESULTADOS}

Os quatro sagüis inoculados com a amostra de $L$. donovani isolada do paciente desenvolveram a infecção, evidenciada pela presença do parasito no material obtido das respectivas biópsias hepáticas.

No grupo dos animais que receberam as séries de antimonial, tanto os "imprints" de baço, fígado, esfregaços de medula óssea, culturas nos meios de Lit, Agar Sangue Difco e Schneider quanto os cortes histológicos de baço, figado e a inoculação em hamsters não se conseguiu demonstrar a presença do parasito após o tratamento. Paralelamente os "imprints" de baço e fígado e esfregaço de medula óssea do animal controle (não tratado) mostraram grande quantidade de amastigotas de $L$. donovani. Esses dados, resumidos na Tabela 1 , não deixam dúvida quanto a resposta terapêutica da amostra de $L$. donovani ao Glucantime.

Tabela 1-Resultados do tratamento com Glucantime, em sagüis (Callithrix jacchus) inoculados com Leishmania donovani (dose $28 \mathrm{mg} \mathrm{Sb} V / \mathrm{kg} /$ dia em três séries de dez dias com cinco dias de intervalo).

\begin{tabular}{|c|c|c|c|c|c|c|c|c|}
\hline $\begin{array}{c}\text { Macaco } \\
N^{o}\end{array}$ & $\begin{array}{l}\text { Punção } \\
\text { hepática }\end{array}$ & $\begin{array}{c}\text { Sacrificio n.o de } \\
\text { semanas após o } \\
\text { tratamento }\end{array}$ & $\begin{array}{l}\text { "Im } \\
\text { Baço }\end{array}$ & $\begin{array}{l}\text { prints" } \\
\text { Figado }\end{array}$ & $\begin{array}{l}\text { Esfregaço de } \\
\text { medula óssea }\end{array}$ & $\begin{array}{r}\text { Cultura } \\
\text { Bą̧o + Fígado }\end{array}$ & Sangue & $\begin{array}{l}\text { Inoculação de supensão } \\
\text { de figado }+ \text { baço em dois } \\
\text { hamsters }\end{array}$ \\
\hline $8 \mathrm{M}$ & + & 3 & - & - & - & - & - & - \\
\hline $10 \mathrm{M}$ & + & 3 & - & - & - & - & - & - \\
\hline & + & 4 & - & - & - & - & - & - \\
\hline $7 \mathrm{M}$ (Controle) & + & 4 & + & + & + & NF & NF & $\mathrm{NF}$ \\
\hline
\end{tabular}

NF - Não feito 
Dietze $R$, Araújo RC, Lima MLR, Vexenat JA, Marsden PD, Barreto AC. Ensaio terapêutico com glucantime em sagüis (Callithrix jacchus) infectados com uma cepa de Leishmania donovani aparentemente resistente ao tratamento. Revista da Sociedade Brasileira de Medicina Tropical 18: 39-42, Jan-Mar, 1985

\section{DISCUSSÃO}

O fato da amostra de L. donovani no paciente ter sido resistente aos vários tratamentos e ter sido sensivel em modelo experimental à terapêutica com glucantime, afasta a possibilidade de resistência primária do parasito à droga. A resistência do protozoário aos agentes antimoniais, apesar de sempre presente nas discussões sobre fracasso terapêutico, só recentemente foi demonstrada por Berman e cols $^{4}$, em experimento "in vitro" utilizando cultura de macrófagos. Por outro lado, esses autores mostraram susceptibilidade aos antimoniais de amostras de leishmanias isoladas de pacientes que não responderam à terapêutica, levando a possibilidade de que a não destruição desses protozoários pelos macrófagos poderia estar na incapacidade dessas células em metabolizar a droga, convertendo-a em produto ativo, capaz de destruir o parasito.

Outras hipóteses poderiam ser levantadas na tentativa de explicar a evolução anormal deste caso como por exemplo, fatores farmacodinâmicos ligados à dosagem, via de administração, absorção e perfusão da droga nos locais onde se encontram os parasitos, ou fatores imunológicos como a capacidade de resposta do paciente ao agente agressor, com uma imunidade celular e humoral eficazes.

A farmacologia dos antimoniais pentavalentes foi reavaliada recentemente por Rees e cols ${ }^{19}$ e Chulay e cols 9 , que mostraram ser essas substâncias rapidamente eliminadas na urina, com 81 a $97 \%$ da droga sendo excretada nas primeiras 6 a $8 \mathrm{~h}$, com uma meia vida em torno de duas horas. Paralelamente a essa excreção renal ocorre um discreto acúmulo no organismo de $\mathrm{Sb}^{\mathrm{v}}$ que tende a se estabilizar por volta do 10 \% dia de aplicação ${ }^{9}$. Tais dados tem levado pesquisadores e clínicos a usar com sucesso nos pacientes que não respondem ao esquema tradicional, doses progressivamente maiores de antimoniais por tempo mais prolongado sem que com isso tenham notado aumento significativo dos seus efeitos colaterais 8 . Infelizmente não podemos saber até que ponto o nosso paciente se beneficiaria com esquema terapêutico usando doses maiores de $\mathrm{Sb}^{\mathbf{v}}$ apesar de termos administrado Pentostam de modo contínuo por 30 dias. De qualquer forma seria difícil explicar a falha de resposta clínica do paciente ao esquema terapêtico "per se" se levarmos em conta que nos animais tratados ocorreu cura com posologia e tempo de tratamento semelhantes ao utilizado no doente. Contudo, apesar de já terem sido avaliados como modelo experimental ${ }^{15}$, não sabemos até que ponto os resultados obtidos nesses animais podem ser extrapolados para o homem.

Discute-se atualmente a possibilidade de haver uma depressão na imunidade mediada por células nos pacientes com calazar. Essa depressão, caracterizada como baixa de resposta linfoproliferativa "in vitro" a estimulos antigênicos, seria especifica para antigenos do parasita e reversível após cura da doença 710. Carvalho e cols 6 mostraram que, além desse aspecto, os linfócitos de indivíduos com calazar não são capazes de produzir linfocinas quando estimulados com antígenos de $L$. mexicana. Esses achados estão de acordo com a observação de que estes pacientes não apresentam reação de hipersensibilidade do tipo retardado, quando inoculados por via intradérmica, com antigeno de Leishmania (reação de Montenegro) ${ }^{1}$.

Os testes cutâneos realizados em nosso paciente na avaliação da imunidade celular foram negativos, a exceção da capacidade de sensibilização pelo DNCB. Esses resultados não diferem daqueles encontrados em nosso meio, nos pacientes com calazar ${ }^{1}$.

Recentemente, Murray e cols ${ }^{17}$ demonstraram in vitro que a incapacidade do sistema fagocítico mononuclear em destruir as leishmânias fagocitadas seria devida à deficiência de interferon gama, linfocina ativadora de macrófagos, principais responsáveis pela destruição do protozoário.

Apesar de ainda não estar definido o real papel da imunidade celular na leishmaniose, a hipótese de que uma deficiência desta natureza possa ter influido na evolução clínica deste caso não pode ser afastada.

\section{SUMMARY}

The authors describe a therapeutic study in marmosets (Callithrix jacchus) of a strain of Leishmania donovani isolated from a fatal human case of Kala-azar. The patient failed to respond to antimonials (Glucantime and Pentostam), Amphotericin $B$ and pentamidine therapy. Skin tests for the evaluation of cellular immunity were negative with the exception of $2 \%$ dinitrochlobenzene. Four adult marmosets were inoculated intraperitoneally with a suspension of amastigotes of $\mathrm{L}$. donovani isolated from the hamster liver and spleen. Two hundred and ten days later all the animals had amastigotes in aspirates obtained by liver puncture. Glucantime treatment $28 \mathrm{mg} /$ kilogram body weight per day for 3 series of 10 days was begun in three animals while the fourth was kept as a control. The three treated animals became parasite free in contrast to the control marmoset. The fact that this strain of $\mathrm{L}$. dono- 
Dietze R, Araújo RC, Lima MLR, Vexenat JA, Marsden PD, Barreto AC. Ensaio terapêutico com glucantime em sagüis (Callithrix jacchus) infectados com uma cepa de Leishmania donovani aparentemente resistente ao tratamento. Revista da Sociedade Brasileira de Medicina Tropical 18: 39-42, Jan-Mar, 1985

vani was unresponsive in the patient, inspite of various attempts at treatment, and yet responded to antimonials in marmosets suggest that the patients immune response was defective leading to a fatal outcome.

Key Words: Kala-azar. Resistence to treatment. Experimental infection in marmosets.

\section{AGRADECIMENTOS}

Agradecemos ao Dr. Edgar M. Carvalho (UFBA) pelas sugestões na discussão do trabalho.

\section{REFERÊNCIAS BIBLIOGRÁFICAS}

1. Andrade TM, Teixeira R, Andrade JAF, Pereira C, Carvalho Filho EM. Estudo da hipersensibilidade do tipo retardado na leishmaniose visceral. Revista do Instituto de Medicina Tropical de São Paulo 24: 298-302, 1982.

2. Andrade TM, Andrade JAF, Badaró R, Bina JC, Carvatho JS, Carvalho EM, Teixeira R. Leishmaniose visceral americana resistente ao antimonial pentavalente (Antimoniato de N-Metilglucamina). XIX Congresso da Sociedade Brasileira de Medicina Tropical, p. 65, 1983.

3. Anonymous. Report of the informal meeting on the chemotherapy of visceral leishmaniasis. World Health Organization. TDR/CHEMILEISH/VL82 3, 1982.

4. Berman JD, Chulay JD, Hendricks LD, Oster CN. Susceptibility of clinically sensitive and resistant Leishmania to pentavalent antimony in vitro. The American Journal Tropical Medicine and Hygiene 31: 459-465, 1982.

5. Camargo EP. Growth and differentiation in Trypanosoma cruzi $\mathrm{I}$. Origin of metacyclic trypanosomes in liquid media. Revista do Instituto de Medicina Tropical de São Paulo 6: 93, 1964.

6. Carvalho EM, Reed S, Inverso J, Rocha H. Cell mediated immunity in visceral leishmaniasis: Evaluation of the capacity to generate lymphokines that increase microbicidal activity. Annual Meeting of the American Society of Tropical Medicine and Hygiene 1983.

7. Carvalho EM, Teixeira RS, Johnson Jr WD. Cell mediated immunity in American visceral leishmaniasis: Reversible immunosuppression during acute infection. Infection and Immunity 33: 498-502, 1981.

8. Chulay JD, Bhatt SM, Muigai R, Ho M, Gachihi G, Were JBO, Chunge C, Bryceson ADM. A comparison of three dosage regimens of sodium stibogluconate in the treatment of visceral leishmaniasis in Kenya. The Journal of Infectious Disease 148: 148-155, 1983.
9. Chulay JD, Smith DH, Pamplin CL. Pharmacokinetics of antimony during treatment of East African Kala-azar with sodium stibogluconate and $\mathrm{N}$-methylglucamine antimoniate: preliminary observations. In: Proceedings of the Second Annual Medical Conference. Africa Science Publishing, Nairobi, Kenya, 1981.

10. Haldar JP, Ghose S., Saha KC, Ghose AC. Cell mediated immune response in Indian kala-azar and post kalaazar dermal leishmaniasis. Infection and Immunity 42: 702-707, 1983.

11. Hendricks LD, Wood DE, Hajduk ME. Haemoflagellates: commercially available liquid media for rapid cultivation. Parasitology 76: 309-316, 1978.

12. Magalhães VB, Cruz MJC, Pitombeira MS. Um caso de calazar resistente aos quimioterápicos tratado pela Anfotericina B. A Folha Médica 32: 99-113, 1966.

13. Manson-Bahr PEC, Wilcocks C. Manson's Tropical Disease. $17{ }^{\circ}$ ed. Bailliere Tindall, London, p. 117-147, 1972.

14. Marsden PD. New light on pentavalent antimonials in the treatment of leishmaniasis. Revista da Sociedade Brasileira de Medicina Tropical 16: 172-174, 1983.

15. Marsden PD, Cuba CC, Vexenat A, Costa e Silva M, Barreto AC. Experimental Leishmania chagasi infections in the marmoset Callithrix jacchus. Transactions of the Royal Society of Tropical Medicine and Hygiene 75: 314-315, 1981.

16. Martins NRLL, Mayrink W, Magalhães P, Neves J. Casos de Leishmaniose visceral americana (Calazar) resistentes tratados pela Anfotericina B. III Congresso da Sociedade Brasileira de Medicina Tropical p. 53, 1967.

17. Murray HW, Rubin BY, Rothermel CD. Killing of intracellular Leishmania donovani by lymphokinestimulated human mononuclear phagocytes. Journal of Clinical Investigation 72: 1506-1510, 1983.

18. Lima MLR, Marsden PD, Pinto AV, Watanabe RC. Apresentação de um caso de leishmaniose visceral resistente ao Antimonial pentavalente. Resumos do XIV Congresso da Sociedade Brasileira de Medicina Tropical, n. $246,1980$.

19. Rees PH, Kager PA, Keating MI, Hockmeyer WT. Renal clearance of pentavalent antimony (Sodium stibogluconate). Lancet 2: 226-29, 1980.

20. Walton BC, Shaw JJ, Lainson R. Observations on "in vitro" cultivation of Leishmania braziliensis. Journal of Parasitology 63: 1118-1119, 1977. 